\title{
Striatal and extrastriatal atrophy in Huntington's disease and its relationship with length of the CAG repeat
}

H.H. Ruocco ${ }^{1}$,

I. Lopes-Cendes², L.M. Li ${ }^{1}$, M. Santos-Silva ${ }^{2}$ and F. Cendes ${ }^{1}$

\author{
${ }^{1}$ Departamento de Neurologia, ${ }^{2}$ Departamento de Genética Médica, \\ Faculdade de Ciências Médicas, Universidade Estadual de Campinas, \\ Campinas, SP, Brasil
}

Correspondence

F. Cendes

Departamento de Neurologia

FCM, UNICAMP

13084-971 Campinas, SP

Brasil

Fax: $+55-19-3289-1818$

E-mail: fcendes@unicamp.br

Research supported by FAPESP (No. 01/05439-3)

Received October 6, 2005

Accepted June 5, 2006

\section{Abstract}

Huntington's disease (HD) is an autosomal dominant neurodegenerative disorder that affects the striatum most severely. However, except for juvenile forms, relative preservation of the cerebellum has been reported. The objective of the present study was to perform MRI measurements of caudate, putamen, cerebral, and cerebellar volumes and correlate these findings with the length of the CAG repeat and clinical parameters. We evaluated 50 consecutive patients with HD using MRI volumetric measurements and compared them to normal controls. Age at onset of the disease ranged from 4 to 73 years (mean: 43.1 years). The length of the CAG repeat ranged from 40 to 69 (mean: 47.2 CAG). HD patients presented marked atrophy of the caudate and putamen, as well as reduced cerebellar and cerebral volumes. There was a significant correlation between age at onset of HD and length of the CAG repeat, as well as clinical disability and age at onset. The degree of basal ganglia atrophy correlated with the length of the CAG repeat. There was no correlation between cerebellar or cerebral volume and length of the CAG repeat. However, there was a tendency to a positive correlation between duration of disease and cerebellar atrophy. While there was a negative correlation of length of the CAG repeat with age at disease onset and with striatal degeneration, its influence on extrastriatal atrophy, including the cerebellum, was not clear. Extrastriatal atrophy occurs later in HD and may be related to disease duration.

\section{Introduction}

Huntington's disease (HD) is a dominantly inherited neurodegenerative disorder that usually manifests in adulthood, resulting in familial adult onset chorea and subcortical dementia (1). In HD, the protein huntingtin is enlarged because of an ex-
Key words

- Neurodegeneration

- Dynamic mutation

- Genotype-phenotype correlation

- Basal ganglia

- Magnetic resonance imaging

- Huntington's disease tended CAG repeat chain present on the short arm of chromosome $4(1,2)$. To date, the exact function of huntingtin is unknown and there is no information about its threedimensional structure that suggests any putative function. The defect of this protein promotes neuronal apoptosis in various brain regions, especially the basal ganglia, and the 
caudate nucleus in particular. Most descriptions were limited exclusively to damage to the striatum (3). However, neuronal degeneration also occurs in other areas of the brain (4-6). Generally the cerebellum is spared in the adult form, and in the great majority of patients the cerebellar changes have been reported to be discrete $(5,6)$.

The length of the CAG repeat in the mutant gene has important implications for age at onset, penetrance, and stability of the gene between generations (7). While the relationship between CAG repeat and age at onset is relevant, the effect of trinucleotide length on the rate of HD progression is less clear. Although some investigators have suggested that larger CAG expansions result in more rapid progression (7), two prospective studies have failed to demonstrate a clear relationship between CAG repeat and illness progression (810). A plausible hypothesis to explain this discrepancy point is the instability in the length of the CAG repeat (10).

In the present study, we measured caudate, putamen, cerebral, and cerebellar volumes in a large series of HD patients and controls and we determined whether the HD genotype is associated with regional differences in brain structure, age at onset, duration of disease, and clinical disability.

\section{Subjects and Methods}

\section{Subjects}

All 50 consecutive patients studied had a clinical and molecular diagnosis of HD performed at the Neurogenetics clinic of UNICAMP. For each patient, age at onset of HD was determined by asking the patient and multiple unaffected family members to recollect the first occurrence of chorea, rigidity, irritability, sleep disturbance, frequent falls, sexual dysfunction, loss of energy, altered social behavior, or failing memory that was not an isolated incident but heralded a progressive decline. The control sub- jects, 14 men and 19 women ranging in age from 18 to 55 years (mean age: 34 years; standard deviation, SD: 12.15), were healthy and had no family history of neurological or psychiatric illness. We excluded patients with significant co-morbidities, such as alcoholism, head injury, arterial hypertension, diabetes mellitus, stroke, drug abuse, and malignancy. Neurological exams were performed in all patients by the same investigator (HHR). All subjects gave written informed consent to participate in this study, which was approved by the Ethics Committee of our University Hospital. All patients had known trinucleotide repeats.

\section{Clinical and molecular investigation}

We used a structured clinical questionnaire for patients and family members. Each subject underwent formal motor examination. Subjects were scored according to the motor component of the United Huntington's Disease Rating Scale (UHDRS) (11). Clinical and genetic details of each patient were included in a database. Molecular testing was performed according to international standard protocols for laboratory testing of HD. Genomic DNA was isolated from peripheral lymphocyte by standard methods. PCR amplification of the CAG repeat in the IT15 gene was performed with primers HD1 and HD3 $(1,12)$, which are adjacent to the CAG stretch. PCR reactions were performed in a total volume of $12.5 \mu \mathrm{L}$ containing 100 ng of genomic DNA, 1.6 MM of each dNTP (dATP, dGTP, dTTP), 4 pmol of each primer, 5\% DMSO, 0.2 U perfect match (Stratagene ${ }^{\circledR}$, La Jolla, CA, USA), and 0.5 units Taq DNA polymerase. After an initial denaturation of 2 min at $95^{\circ} \mathrm{C}$ the amplification was accomplished in 30 cycles at the following temperatures: denaturing at $94^{\circ} \mathrm{C}$ for $1 \mathrm{~min}$, annealing at $50^{\circ} \mathrm{C}$ for $1 \mathrm{~min}$, and extension at $72^{\circ} \mathrm{C}$ for $2 \mathrm{~min}$, followed by a final extension at $72^{\circ} \mathrm{C}$ for $7 \mathrm{~min}$. PCR products were separated by electrophoreses through a $6 \%$ dena- 
turing polyacrylamide gel. Gels were transferred into Hybond $\mathrm{N}+$ nylon membranes and hybridized with an $\alpha{ }^{32} \mathrm{P} 3$ '-end labeled (CAG) 15 probe. Allele lengths were determined by comparing migration relative to a sequencing ladder. Alleles were considered normal when they contained less than 35 CAGs and expanded when they contained more than 40 CAGs (13). We then assigned the patients to three subgroups: patients with early onset $\mathrm{HD}(\mathrm{N}=4,2$ males and 2 females, mean age at onset 8 years), patients with classical onset $\mathrm{HD}(\mathrm{N}=24,8$ males and 16 females, mean age at onset 30 years), and patients with late onset $\mathrm{HD}(\mathrm{N}=22,19$ males and 3 females, mean age at onset 44 years).

\section{Magnetic resonance imaging acquisition}

Magnetic resonance imaging was obtained with a 2 Tesla system (Elscint Prestige ${ }^{\circledR}$, Haifa, Israel). Images were acquired on the coronal, sagittal, and axial planes. Our HD protocol consists of: a) sagittal T1 spin-echo, $6 \mathrm{~mm}$ thick (repetition time (TR), 430; echo time (TE), 12) for optimal orientation of the subsequent images; b) coronal $\mathrm{T} 1$ inversion recovery, $3 \mathrm{~mm}$ thick (flip angle $=200^{\circ}$; $\mathrm{TR}=2700$ $\mathrm{ms} ; \mathrm{TE}=14 \mathrm{~ms} ; \mathrm{T} 1=840 \mathrm{~ms} ;$ matrix $=130 \mathrm{x}$ 256; field of view $(\mathrm{FOV})=16 \times 18 \mathrm{~cm})$; c) coronal T2-weighted fast spin-echo, $3 \mathrm{~mm}$ thick (flip angle $=120^{\circ} ; \mathrm{TR}=4800 \mathrm{~ms}$; $\mathrm{TE}=$ 129 ms; matrix $=252 \times 320 ; \mathrm{FOV}=18 \times 18$ $\mathrm{cm})$;) axial images parallel to the long axis of the hippocampus; T1 gradient echo, $3 \mathrm{~mm}$ thick (flip angle $=70^{\circ}$; TR $=200 \mathrm{~ms} ; \mathrm{TE}=5$ ms; matrix $=180 \times 232 ; \mathrm{FOV}=22 \times 22 \mathrm{~cm}$ ); e) axial T2 fast spin-echo, $4 \mathrm{~mm}$ thick (flip angle $=120^{\circ} ; \mathrm{TR}=6800 \mathrm{~ms} ; \mathrm{TE}=129 \mathrm{~ms}$; matrix $=252 \times 328 ; \mathrm{FOV}=21 \times 23 \mathrm{~cm}$ ).

\section{Volumetric studies}

Basal ganglia and cerebral volumes were measured using coronal inversion recovery images and cerebellar volume was measured using sagittal T1 spin-echo acquisition. Caudate and putamen structures and total intracranial and cerebellar volumes (Figure 1) were manually delineated using the NIH Image program (http://rsb.info.nih.gov/nihimage). The volume of each region was compared to that of the control group of 33 healthy volunteers. Values below two SD from the mean for the control group were considered abnormal.
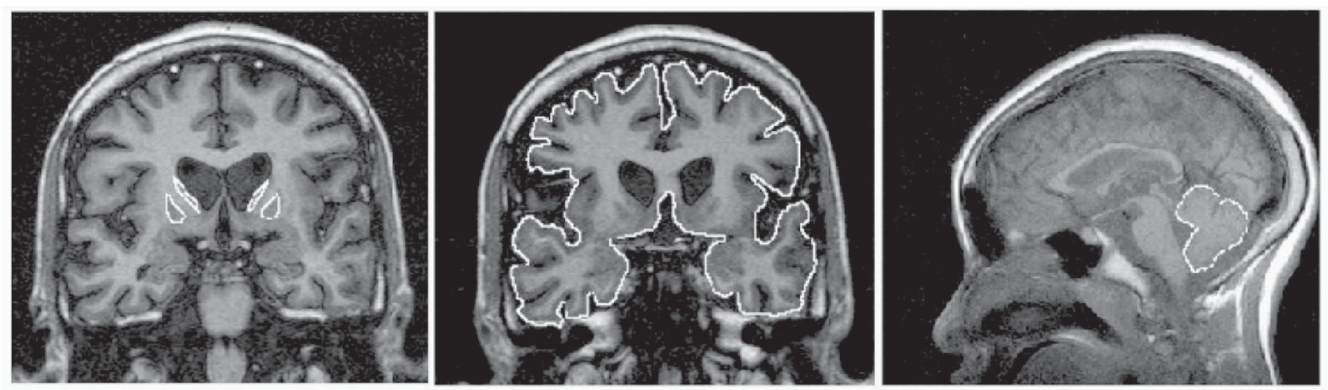

Figure 1. Samples of coronal and sagittal magnetic resonance imaging from a patient with Huntington's disease (top row) and a normal control (bottom row) showing the outlines of caudate and putamen (left), cerebral (center) and cerebellar volumes (right).
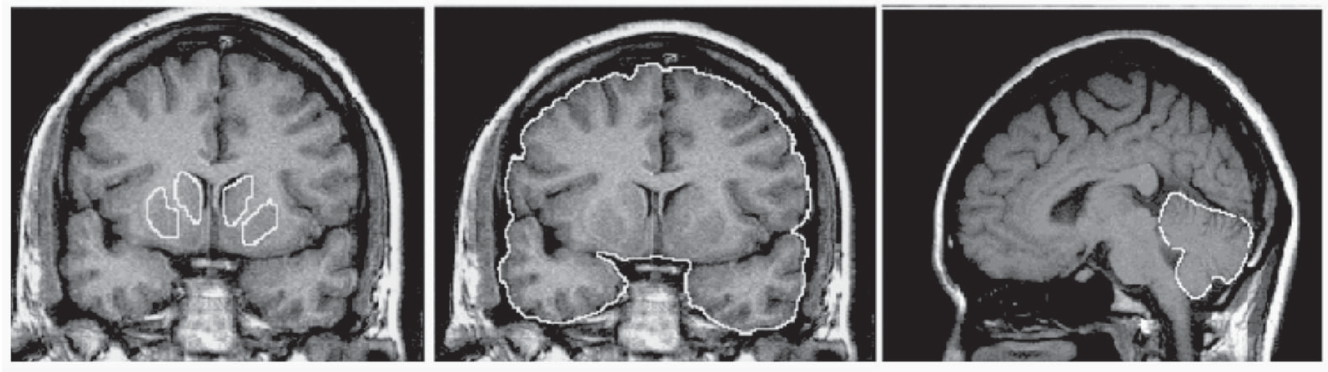


\section{Statistical analysis}

We report the minimum, maximum and mean values and SD for the volumes of the structures analyzed, and $\mathrm{P}$ values less than 0.05 were accepted as statistically significant. We used analysis of variance (ANOVA) to compare continuous variables between groups. Left/right asymmetry (asymmetric index, AI) was calculated according to the following formula: $\mathrm{AI}=(\mathrm{left}-$ right $) / 0.5$ (left + right). To assess the relationship between volumes and length of the CAG repeat, and age at onset of the disease we used Spearman correlation analysis. We used the Mann-Whitney test to compare AI between right and left basal ganglia structures and cerebellar and cerebral volumes. We used linear regression to assess the relationship between age at onset of disease and length of the $\mathrm{CAG}$ repeat. For the clinical score analyses we used the Spearman correlation test.

We also performed statistical analyses

Figure 2. Box plot with putamen $(A)$, caudate $(B)$, cerebellar $(C)$, and cerebral (D) volumes in 50 patients with Huntington's disease (HD) and 33 controls (C). The box extends from the 25th percentile to the 75 th percentile, with a horizontal line at the median (50th percentile). Whiskers extend down to the smallest value and up to the largest. RHD $=$ right-sided volumes in patients with HD; LHD = left-sided volumes in patients with $\mathrm{HD}$; RC = right-sided volumes in controls; $\mathrm{LC}=$ left-sided volumes in controls. There was a significant difference between patients and controls for all comparisons $(\mathrm{P}<$ 0.0001 ; ANOVA for basal ganglia and Mann-Whitney test for cerebellar and cerebral volumes).

\section{A}


comparing the three subgroups of HD subjects according to age at disease onset. We used ANOVA to compare continuous variables between groups such as putamen and caudate nuclei, and clinical analysis. We used the exact Mann-Whitney test to compare cerebellar and cerebral volumes between HD and control groups and the Kruskal-Wallis test when these structures were compared with the three subgroups of HD.

\section{Results}

We studied 50 consecutive patients with a clinical and molecular diagnosis of HD (21 women and 29 men; mean age: 43.1 years; SD: 13.25 ; range: 4 to 73 years) and compared them to normal controls (14 men and 19 women) ranging in age from 18 to 55 years (mean: 34 years; SD: 12.15). The age at onset of HD ranged from 2 to 66 years (mean: 35.1 years; SD: 12.19). Among patients followed at our HD clinic we identi-
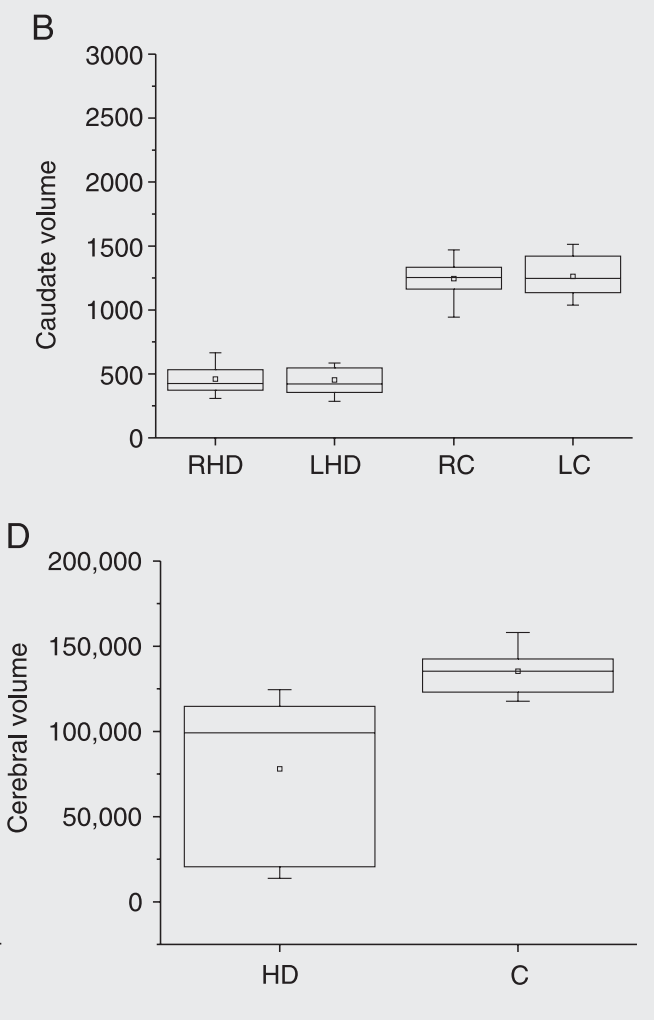
fied 4 patients with the juvenile form of the disease ( 2 women) with a mean age of 14.5 years (SD: 7.85 ; range: 4 to 21 years) that were analyzed separately. The CAG repeat in the HD gene ranged from 40 to 69 (mean: 47.2 CAG; SD: 5.87) and normal alleles ranged from 18 to $26 \mathrm{CAG}$ units (mean: 22 CAG; SD: 2.65). There was no significant difference in the length of the expanded alleles between affected men (mean 45.7; SD: 3.30) and affected women (mean 49.1; SD: $7.86 ; P=0.08$ ). There was a significant inverse correlation between age at onset of the disease and length of the CAG repeat ( $\mathrm{P}$ $=0.0001, r=-0.60$, Spearman test), but not between duration of disease and length of the $\mathrm{CAG}$ repeat $(\mathrm{P}=0.54, \mathrm{r}=-0.08)$. There was a marked reduction of caudate and putamen nuclei and of cerebral and cerebellar volume in HD patients, with a significant difference from controls $(\mathrm{P}<0.0001$; Figure 2 ). Left-sided putamen volumes were slightly smaller than right-sided putamen volumes $(\mathrm{P}=0.05)$, but there was no asymmetry for the caudate. There was a significant correlation between the length of the CAG repeat and the volumes of right caudate $(\mathrm{P}=0.024$, $\mathrm{r}=-0.31)$, left caudate $(\mathrm{P}=0.0047, \mathrm{r}=$ $-0.39)$, right putamen $(\mathrm{P}=0.023, \mathrm{r}=-0.32)$, and left putamen nuclei $(\mathrm{P}=0.05, \mathrm{r}=-0.27)$. However, there was no correlation between putamen and caudate volumes and duration of disease $(\mathrm{P}=0.53, \mathrm{r}=0.09$ for right putamen; $\mathrm{P}=0.60, \mathrm{r}=0.07$ for left putamen; $\mathrm{P}=0.43, \mathrm{r}=-0.11$ for right caudate; $\mathrm{P}=0.49$, $r=-0.10$ for left caudate). In addition, we did not find a correlation between the length of the CAG repeat and cerebellar $(\mathrm{P}=0.72, \mathrm{r}=$ $-0.05)$ or cerebral $(\mathrm{P}=0.91, \mathrm{r}=-0.01)$ volumes. We found a tendency to a correlation between duration of disease and cerebellar volumes $(P=0.08, r=-0.25)$, but not cerebral volumes $(\mathrm{P}=0.48, \mathrm{r}=-0.10)$.

When the juvenile group was compared to the group of classic and late onset HD, there was no statistical difference in basal ganglia, cerebellar or cerebral volume $(\mathrm{P}=$
$0.1, \mathrm{P}=0.4$, and $\mathrm{P}=0.3$, respectively). In addition, we found a highly significant difference in the mean size of the expanded allele between early- and late-onset HD and between classic-onset and late-onset HD (P $<0.05)$.

The UHDRS scores ranged from 15 to 128 (mean: 65.5; SD: 33.74; Table 1). There was a correlation between UHDRS scores and age at onset $(\mathrm{P}=0.03, \mathrm{r}=0.3)$, and a tendency for length of the CAG repeat $(\mathrm{P}=$ $0.08, r=0.24)$, but there was no correlation between duration of disease, cerebral volume, right putamen and caudate volumes, and clinical scores $(\mathrm{P}>0.1)$. Interestingly, there was a correlation between UHDRS scores and left putamen volume and a tendency to a correlation between UHDRS score and left caudate volume $(\mathrm{P}=0.05, \mathrm{r}=0.27$ and $\mathrm{P}=0.07, \mathrm{r}=0.25$, respectively).

\section{Discussion}

Since the original discovery that the HD phenotype results from an expanded CAG trinucleotide repeat within the IT15 gene located on chromosome $4(1,2)$, several hypotheses have been raised in an attempt to explain the mechanisms of expanded CAG repeats in the pathogenesis of HD. Certain

\begin{tabular}{|c|c|c|}
\hline & $\begin{array}{l}\text { Huntington's disease } \\
\qquad(\mathrm{N}=50)\end{array}$ & $\begin{array}{l}\text { Normal controls } \\
\qquad(\mathrm{N}=33)\end{array}$ \\
\hline Male:female & 29:21 & $14: 19$ \\
\hline Age (years; range) & $4-73$ & $18-55$ \\
\hline Age (years; mean $\pm S D$ ) & $43.1 \pm 13.25$ & $34 \pm 12.15$ \\
\hline Age at onset (years; range) & $2-66$ & \\
\hline Age at onset (years; mean \pm SD) & $35.1 \pm 12.19$ & \\
\hline CAG repeat (range) & $40-69$ & $18-26$ \\
\hline $\mathrm{CAG}$ repeat $($ mean $\pm \mathrm{SD})$ & $47.2 \pm 5.87$ & $22 \pm 2.65$ \\
\hline UHDRS (range) & $15-128$ & \\
\hline UHDRS (mean $\pm \mathrm{SD})$ : & $65.5 \pm 33.74$ & \\
\hline CAG repeat (men; mean $\pm S D$ ) & $45.7 \pm 3.30$ & \\
\hline CAG repeat (women; mean $\pm \mathrm{SD}$ ) & $49.1 \pm 7.86$ & \\
\hline
\end{tabular}

UHDRS $=$ United Huntington's Disease Rating Scale. 
brain areas and also specific neuronal subtypes differ significantly in their susceptibility to injury in the course of acute and chronic disorders, suggesting that specific protective factors are expressed differently among neurons or even among different cell types in the same tissue. This can be clearly seen in the striatum, where GABAergic projection cells (12,14-16), but not cholinergic interneurons, are precociously damaged in the course of HD (12,15-18).

There is evidence of distributed gray matter pathology and progressive white matter pathology before the clinical onset of HD $(5,19)$, and loss of basal ganglia volume has also been reported in asymptomatic individuals with HD mutation (20-24), indicating that striatal neuronal loss occurs before or early during the clinical course.

Even though striatal atrophy has been detected and reported by many investigators (3,25-29), neuronal degeneration also occurs in other areas of the brain such as the cerebral and cerebellar cortex (4,5), amygdala, hippocampus, and brainstem (6), supporting the concept that HD is a multisystem disorder. In agreement with this concept, subcortical gray matter loss in the thalamus, substantia nigra, and anterior basomedial diencephalic region has been described, but in later stages of the disease (5).

It is well known that the most affected brain structure in HD patients is the striatum (3). However, the mechanisms underlying the regional preferences for striatum atrophy are still controversial. One possible explanation is the instability in the length of the CAG stretch (10). The resulting polyglutamine load can vary as a result of the regional instability of the CAG mutation related to the tissue biochemical features (30), therefore causing different rates of cell death in different tissues. On the other hand, there is some evidence that polyglutamine differs between tissues due to differential instability of the CAG mutation (30). Perhaps then the striatum is more vulnerable to the effects of accumulating mutant huntingtin than other tissues. Curiously, in our study left-sided putamen volumes were slightly smaller than right-sided putamen volumes, but we did not find asymmetry in caudate nuclei. Although HD has been generally considered to be a symmetric disease (31), findings of higher lactate levels in the left than in the right striatum have been attributed to increased motor activation in the dominant hemisphere, especially increased glutamatergic synaptic input to striatal cells (32). In agreement with this finding, based on the UHDRS motor component, we detected a slight correlation between clinical disability and left-sided putamen atrophy and a tendency to a correlation between clinical disability and left-sided caudate atrophy. On the other hand, studies have shown that the putamen is more affected than the caudate $(27,28)$, whereas others have shown the opposite $(20,29)$. Longitudinal data from neuropathology and neuroimaging studies suggest that the earliest changes in HD occur in the caudate nucleus, while the putamen nucleus is more affected with disease progression $(3,33,34)$. In agreement with previous studies $(29,31,35,36)$, we found that the caudate and putamen were disproportionately atrophic in HD patients, with this atrophy correlating with the length of the CAG repeat, but not with duration of the disease $(23,37)$. On the other hand, atrophy also occurred in cerebral and cerebellar volumes, but without correlation with the length of the CAG repeat $(29,36)$. In addition, there was a non-significant trend towards an inverse correlation between cerebellar atrophy and duration of the disease. This may support the hypothesis that neocortical and cerebellar degenerations are explained, at least in part, by retrograde changes due to massive neuronal loss in the striatum or due to progressive white matter loss in the course of the disease, suggesting that cerebellar neuronal loss occurs later in the clinical course.

The present results suggest a more wide- 
spread and global disease process in patients with HD, and that the extent of the degeneration process is not completely explained by the length of the CAG repeat. Recent evidence showed that environmental factors modify the onset and progression of neurodegeneration (38) and variations in the glutamate receptor 6 genotype may explain up to $13 \%$ of the variability in the age at onset of
HD not accounted for by the length of the CAG repeat $(39,40)$.

Longitudinal studies with larger series will be necessary to characterize the exact rate of atrophy of different brain structures and to determine the kinetics of neuronal degeneration during the various stages of HD and this knowledge could be helpful for the targeting of new therapeutic measures.

\section{References}

1. Huntington's Disease Collaborative Research Group. A novel gene containing a trinucleotide repeat that is expanded and unstable on Huntington's disease chromosomes. Cell 1993; 72: 971-983.

2. Gusella JF, Wexler NS, Conneally PM, Naylor SL, Anderson MA, Tanzi RE, et al. A polymorphic DNA marker genetically linked to Huntington's disease. Nature 1983; 306: 234-238.

3. Vonsattel JP, Myers RH, Stevens TJ, Ferrante RJ, Bird ED, Richardson Jr EP. Neuropathological classification of Huntington's disease. J Neuropathol Exp Neurol 1985; 44: 559-577.

4. Kassubek J, Bernhard LG, Ecker D, Juengling FD, Muche R, Schuller S, et al. Global cerebral atrophy in early stages of Huntington's disease: quantitative MRI study. Neuroreport 2004; 15 : 363-365.

5. Fennema-Notestine C, Archibald SL, Jacobson MW, Corey-Bloom J, Paulsen JS, Peavy GM, et al. In vivo evidence of cerebellar atrophy and cerebral white matter loss in Huntington disease. Neurology 2004; 63: 989-995.

6. Rosas HD, Koroshetz WJ, Chen YI, Skeuse C, Vangel M, Cudkowicz $\mathrm{ME}$, et al. Evidence for more widespread cerebral pathology in early HD: an MRI-based morphometric analysis. Neurology 2003; 60: 1615-1620.

7. Brandt J, Bylsma FW, Gross R, Stine OC, Ranen N, Ross CA. Trinucleotide repeat length and clinical progression in Huntington's disease. Neurology 1996; 46: 527-531.

8. Kieburtz K, MacDonald M, Shih C, Feigin A, Steinberg K, Bordwell $\mathrm{K}$, et al. Trinucleotide repeat length and progression of illness in Huntington's disease. J Med Genet 1994; 31: 872-874.

9. Kremer B, Clark CM, Almqvist EW, Raymond LA, Graf P, Jacova C, et al. Influence of lamotrigine on progression of early Huntington disease: a randomized clinical trial. Neurology 1999; 53: 1000-1011.

10. Andrew SE, Goldberg YP, Kremer B, Telenius H, Theilmann J, Adam $S$, et al. The relationship between trinucleotide (CAG) repeat length and clinical features of Huntington's disease. Nat Genet 1993; 4: 398-403.

11. Huntington Study Group. Unified Huntington's Disease Rating Scale: reliability and consistency. Mov Disord 1996; 11: 136.

12. Mitchell IJ, Cooper AJ, Griffiths MR. The selective vulnerability of striatopallidal neurons. Prog Neurobiol 1999; 59: 691-719.

13. American College of Medical Genetics/American Society of Human Genetics Huntington Disease Genetic Testing Working Group. ACMG/ASHG statement. Laboratory guidelines for Huntington disease genetic testing. Am J Hum Genet 1998; 62: 1243-1247.

14. Pulsinelli WA. Selective neuronal vulnerability: morphological and molecular characteristics. Prog Brain Res 1985; 63: 29-37.
15. Beal MF, Kowall NW, Ellison DW, Mazurek MF, Swartz KJ, Martin JB. Replication of the neurochemical characteristics of Huntington's disease by quinolinic acid. Nature 1986; 321: 168-171.

16. Calabresi P, Ascone CM, Centonze D, Pisani A, Sancesario G, D'Angelo $\mathrm{V}$, et al. Opposite membrane potential changes induced by glucose deprivation in striatal spiny neurons and in large aspiny interneurons. J Neurosci 1997; 17: 1940-1949.

17. Calabresi P, Centonze D, Pisani A, Bernardi G. Metabotropic glutamate receptors and cell-type-specific vulnerability in the striatum: implication for ischemia and Huntington's disease. Exp Neurol 1999; 158: 97-108.

18. Pisani A, Bonsi P, Centonze D, Giacomini P, Calabresi P. Involvement of intracellular calcium stores during oxygen/glucose deprivation in striatal large aspiny interneurons. J Cereb Blood Flow Metab 2000; 20: 839-846.

19. Thieben MJ, Duggins AJ, Good CD, Gomes L, Mahant N, Richards $\mathrm{F}$, et al. The distribution of structural neuropathology in pre-clinical Huntington's disease. Brain 2002; 125: 1815-1828.

20. Aylward EH, Brandt J, Codori AM, Mangus RS, Barta PE, Harris GJ. Reduced basal ganglia volume associated with the gene for Huntington's disease in asymptomatic at-risk persons. Neurology 1994; 44: 823-828.

21. Harris GJ, Codori AM, Lewis RF, Schmidt E, Bedi A, Brandt J. Reduced basal ganglia blood flow and volume in pre-symptomatic, gene-tested persons at-risk for Huntington's disease. Brain 1999; 122 (Pt 9): 1667-1678.

22. Penney Jr JB, Vonsattel JP, MacDonald ME, Gusella JF, Myers RH. CAG repeat number governs the development rate of pathology in Huntington's disease. Ann Neurol 1997; 41: 689-692.

23. Albin RL. Selective neurodegeneration in Huntington's disease. Ann Neurol 1995; 38: 835-836.

24. Kowall NM, Ferrante RJ, Martin JB. Patterns of cell loss in Huntington's disease. Trends Neurosci 1987; 10: 24-29.

25. Starkstein SE, Brandt J, Folstein S, Strauss M, McDonnell A, Folstein $M$. Brain atrophy in Huntington's disease: correlations with clinical and neuropsychological findings. Neurology 1988; 38 (Suppl 1): 359.

26. Grafton ST, Mazziotta JC, Pahl JJ, St George-Hyslop P, Haines JL, Gusella J, et al. Serial changes of cerebral glucose metabolism and caudate size in persons at risk for Huntington's disease. Arch Neurol 1992; 49: 1161-1167.

27. Aylward EH, Codori AM, Barta PE, Pearlson GD, Harris GJ, Brandt $J$. Basal ganglia volume and proximity to onset in presymptomatic Huntington disease. Arch Neurol 1996; 53: 1293-1296.

28. Harris GJ, Pearlson GD, Peyser CE, Aylward EH, Roberts J, Barta 
$\mathrm{PE}$, et al. Putamen volume reduction on magnetic resonance imaging exceeds caudate changes in mild Huntington's disease. Ann Neurol 1992; 31: 69-75.

29. de la Monte SM, Vonsattel JP, Richardson Jr EP. Morphometric demonstration of atrophic changes in the cerebral cortex, white matter, and neostriatum in Huntington's disease. J Neuropathol Exp Neurol 1988; 47: 516-525.

30. Kennedy L, Shelbourne PF. Dramatic mutation instability in HD mouse striatum: does polyglutamine load contribute to cell-specific vulnerability in Huntington's disease? Hum Mol Genet 2000; 9: 2539-2544.

31. Rosas HD, Goodman J, Chen YI, Jenkins BG, Kennedy DN, Makris $\mathrm{N}$, et al. Striatal volume loss in HD as measured by MRI and the influence of CAG repeat. Neurology 2001; 57: 1025-1028.

32. Jenkins BG, Rosas HD, Chen YC, Makabe T, Myers R, MacDonald $\mathrm{M}$, et al. 1H NMR spectroscopy studies of Huntington's disease: correlations with CAG repeat numbers. Neurology 1998; 50: 1357 1365.

33. Aylward EH, Li Q, Stine OC, Ranen N, Sherr M, Barta PE, et al. Longitudinal change in basal ganglia volume in patients with Huntington's disease. Neurology 1997; 48: 394-399.

34. Oyanagi K, Takeda S, Takahashi H, Ohama E, Ikuta F. A quantitative investigation of the substantia nigra in Huntington's disease. Ann Neurol 1989; 26: 13-19.
35. Wexler NS, Lorimer J, Porter J, Gomez F, Moskowitz C, Shackell E, et al. Venezuelan kindreds reveal that genetic and environmental factors modulate Huntington's disease age of onset. Proc Natl Acad Sci U S A 2004; 101: 3498-3503.

36. Sieradzan K, Mann DM, Dodge A. Clinical presentation and patterns of regional cerebral atrophy related to the length of trinucleotide repeat expansion in patients with adult onset Huntington's disease. Neurosci Lett 1997; 225: 45-48.

37. Furtado S, Suchowersky O, Rewcastle B, Graham L, Klimek ML Garber A. Relationship between trinucleotide repeats and neuropathological changes in Huntington's disease. Ann Neurol 1996; 39: 132-136.

38. Hockly E, Cordery PM, Woodman B, Mahal A, van Dellen A, Blakemore $\mathrm{C}$, et al. Environmental enrichment slows disease progression in R6/2 Huntington's disease mice. Ann Neurol 2002; 51: 235-242.

39. MacDonald ME, Vonsattel JP, Shrinidhi J, Couropmitree NN Cupples LA, Bird ED, et al. Evidence for the GluR6 gene associated with younger onset age of Huntington's disease. Neurology 1999; 53: $1330-1332$

40. Rubinsztein DC, Leggo J, Chiano M, Dodge A, Norbury G, Rosser E, et al. Genotypes at the GluR6 kainate receptor locus are associated with variation in the age of onset of Huntington disease. Proc Natl Acad Sci U S A 1997; 94: 3872-3876. 